\title{
Characterization of Phosphate-Containing Metabolites by Calcium Adduction and Electron Capture Dissociation
}

\author{
Haichuan Liu, ${ }^{*}$ Hyun Ju Yoo, and Kristina Håkansson \\ Department of Chemistry, University of Michigan, Ann Arbor, Michigan, USA
}

Several phosphate-containing metabolites, including nicotinamide adenine dinucleotide (NAD), nicotinamide adenine dinucleotide phosphate (NADP), adenosine $5^{\prime}$-diphosphate ribose (ADP-r), adenosine $5^{\prime}$-triphosphate (ATP), and guanosine $5^{\prime}$-triphosphate (GTP), have been characterized with electron capture dissociation (ECD) and sustained off-resonance irradiation collision-activated dissociation (SORI-CAD) tandem mass spectrometry (MS/MS) in positive-ion mode. Calcium complexation was used to successfully produce abundant doubly charged cationic precursor ions with or without hydration. This approach enabled application of ECD to acidic metabolites for the first time. Fragmentation pathways observed in ECD and SORI-CAD of calcium-adducted phosphate-containing metabolites were complementary. Unique fragmentation was observed in ECD compared to SORI-CAD MS/MS, including ribose cross-ring cleavage for NAD and NADP, and generation of hydrated product ions, including cross-ring fragments, for hydrated ATP and GTP. A combination of ECD and CAD appears promising for maximizing structural information about metabolites. (J Am Soc Mass Spectrom 2008, 19, 799-808) (C) 2008 American Society for Mass Spectrometry

$\mathrm{M}$ etabolites are intermediates and products of metabolism. Systematic investigations of metabolites in cellular metabolism and metabolic regulation have the capability of expanding the understanding of global systems biology, along with genomics, transcriptomics, and proteomics [1-8]. Due to the wide range of metabolites in a metabolic network, and their chemical diversity, it is highly challenging to establish analytical tools for identifying and quantifying all of them. Although nuclear magnetic resonance, Fourier transform infrared, and Raman spectroscopies are widely used for metabolite analysis [5, 9-13], mass spectrometry (MS) has emerged as a more suitable technology for measurement of metabolites because of its wide dynamic range $\left(10^{4}-10^{6}\right)$, good sensitivity $(\mathrm{nM})$, and ability to detect a diverse number of molecular species [14-16].

Phosphate-containing metabolites are mainly involved in the central carbon metabolism, which consists of glycolysis, the pentose-phosphate pathway, the tricarboxylic acid cycle, and their corresponding cofactors. Tandem mass spectrometry (MS/MS) and exact mass measurements of intracellular metabolites have led to the identification of metabolites for improved understanding of bio-

Address reprint requests to Dr. Kristina Håkansson, University of Michigan, Department of Chemistry, 930 North University Avenue, Ann Arbor, MI 48109-1055, USA. E-mail: kicki@umich.edu

* Present address: Department of Cell and Tissue Biology, University of California San Francisco, 513 Parnassus Avenue, San Francisco, CA 941430512, USA logical pathways and discovery of potential biomarkers [17-21]. MS/MS involving collision-activated dissociation (CAD) has been used to obtain structural information about phosphate-containing metabolites [17-20, 22-24]. In such experiments, negative-mode ionization is generally preferred due to the acidic character of phosphate groups [17-20, 22-25]. Negative-mode CAD of phosphate-containing metabolites often results in limited fragmentation, possibly due to the absence of a mobile proton [26], and thereby provides limited structural information because it mainly results in cleavages at phosphate groups, or charge-directed fragmentation [18, 19, 23]. However, Gross and coworkers have recently shown that highenergy CAD of metabolite anions in a matrix-assisted laser desorption/ionization tandem time-of-flight mass spectrometer allows differentiation between isomeric metabolites such as adenosine $5^{\prime}$-triphosphate (ATP) and 2'-deoxyguanosine 5'-triphosphate (dGTP) [25].

Fourier transform ion cyclotron resonance (FT-ICR) mass spectrometry provides several advantages for metabolite analysis. The accurate mass capabilities and ultrahigh resolution of FT-ICR MS are highly valuable for the identification of unknown metabolites from highly complex metabolite mixtures [7, 14, 27]. In addition, FT-ICR MS offers MS/MS techniques other than CAD, such as electron capture dissociation (ECD) [28, 29], electron induced dissociation (EID) [30-32], and infrared multiphoton dissociation (IRMPD) [33, 34]. We recently demonstrated that IRMPD and EID constitute valuable alternative fragmentation strategies for 
identification of phosphate-containing metabolites in negative-ion mode [35]. IRMPD and EID of phosphatecontaining metabolite anions provided additional structural information due to complementary fragmentation pathways as compared to CAD, particularly for heavier phosphate-containing metabolites and metabolites containing several phosphate groups [35]. Another alternative approach may be to allow positive-ion mode analysis. We have shown that divalent metal ions can be used as efficient charge carriers for sulfated peptides [36] and for oligosaccharides [37]. In both cases, utilization of a divalent metal allowed formation of doubly charged cations, which are required for ECD. In addition, the signal abundance increased compared to protonation.

ECD, introduced by Zubarev and colleagues in 1998 [29], involves irradiation of multiply charged cationic analytes with low-energy electrons $(\leq 0.2 \mathrm{eV})$, which generates charge-reduced radical species and product ions $[28,29,38]$. The expanding implementation and application of ECD is a significant advance in biomolecular structural analysis [38-44]. For example, labile post translational modifications in peptides and proteins can be localized with ECD, whereas they are preferentially lost in $\mathrm{CAD}$, thereby precluding their localization [38, 40-43]. ECD has also been shown to yield complementary structural information compared to CAD for other macromolecules, including oligonucleotides [45, 46], lantibiotics [47], and a siderophore [48].

Here, we present utilization of calcium adducts for generation of doubly positively charged phosphatecontaining metabolite ions and for exploration of the fragmentation behavior of the corresponding complexes by ECD. In our previous work [36, 37, 48], $\mathrm{Ca}^{2+}$ was found to be a suitable divalent metal due to its propensity to form abundant complexes with molecules of interest and the analytical utility of the corresponding ECD spectra. In the present work, we also compare ECD with sustained off-resonance irradiation (SORI) CAD [49] of calcium-adducted phosphate-containing metabolites. To our knowledge, this work constitutes the first application of ECD to metabolite analysis (not counting the di- and tripeptides that are frequently part of metabolite databases).

\section{Experimental}

Phosphate-containing metabolites used in this work include nicotinamide adenine dinucleotide (NAD), nicotinamide adenine dinucleotide phosphate (NADP), adenosine $5^{\prime}$-diphosphate ribose (ADP-r), ATP, and guanosine $5^{\prime}$-triphosphate (GTP). All metabolites were purchased from Aldrich (St. Louis, MO, USA) and used without further purification. Doubly positively charged complexes of phosphate-containing metabolites and $\mathrm{Ca}^{2+}$ were generated by external electrospray ionization (ESI) at $70 \mu \mathrm{L} / \mathrm{h}$ (Apollo II ion source with dual ion funnels; Bruker Daltonics, Billerica, MA, USA) of a solution containing 1-5 $\mu \mathrm{M}$ metabolite and 10-20 $\mu \mathrm{M}$ $\mathrm{Ca}^{2+}\left(\mathrm{CaCl}_{2} \cdot 2 \mathrm{H}_{2} \mathrm{O}\right.$ from Fisher, Fair Lawn, NJ, USA).

All mass spectra were collected with an actively shielded 7 Tesla FT-ICR mass spectrometer with a quadrupole front-end (APEX-Q, Bruker Daltonics) as previously described [50]. Briefly, ions produced by ESI were mass-selectively externally accumulated in a hexapole for 1 or $2 \mathrm{~s}$ [51, 52], transferred via high-voltage ion optics, and captured in the ICR cell by dynamic trapping. This accumulation sequence was looped six times to improve precursor ion signal-to-noise ratios (within this number of loops, the signal increases approximately linearly with the number of loops). For ESI, $\mathrm{N}_{2}$ was used as both nebulizing gas (1.5-6 L/s) and drying gas. The drying gas temperature was $200-250{ }^{\circ} \mathrm{C}$, corresponding to the standard temperature for the Apollo II ion source. For MS/MS experiments, massselective external accumulation of $\mathrm{Ca}^{2+}$-adducted metabolites was followed by further isolation via correlated harmonic excitation fields (CHEFs) [53] inside the ICR cell. For ECD, metal-metabolite complexes were irradiated for $100-300 \mathrm{~ms}$ with lowenergy electrons provided by an indirectly heated hollow dispenser cathode [54] at $-1 \mathrm{~V}$ bias voltage. For SORI CAD, an rf frequency offset by $-1000 \mathrm{~Hz}$ from the precursor ion's cyclotron frequency was applied for 2-4 ms while argon was pulsed into the ICR cell to a pressure reading of approximately $10^{-7}$ mbar (gauge calibrated for $\mathrm{N}_{2}$ ). All data were acquired with XMASS (version 6.1, Bruker Daltonics) in broadband mode from $\mathrm{m} / \mathrm{z}=43$ to 1000 with $256-$ $512 \mathrm{~K}$ data points and summed over 8-32 scans. Mass spectra were analyzed with the MIDAS analysis software [55]. A Hanning window function was applied and the data were zero-filled once before magnitude calculation.

\section{Results and Discussion}

\section{ESI Mass Spectra of Phosphate-containing Metabolites in the Presence of $\mathrm{Ca}^{2+}$}

Figure 1 shows positive-ion mode ESI mass spectra of $\mathrm{NAD}, \mathrm{ADP}-\mathrm{r}$, and ATP from $\mathrm{Ca}^{2+}$-containing solutions. Mass spectra of NADP and GTP were similar to those of NAD and ATP, respectively, in terms of the types of ions observed and, therefore, the latter two spectra are not shown. In the absence of divalent metal cations, doubly positively charged $(2+)$ precursors of these phosphate-containing metabolites were not detected (data not shown). By contrast, abundant $2+$ precursors can be seen in ESI MS of solutions containing 1-5 $\mu \mathrm{M}$ phosphate-containing metabolites and an excess amount $(10-20 \mu \mathrm{M})$ of $\mathrm{Ca}^{2+}$ (Figure 1). In ESI MS of NAD (Figure 1a), the most abundant ion is a doubly charged 1:1 complex of NAD and $\mathrm{Ca}^{2+}$, i.e., [NAD + $\mathrm{Ca}^{2+}$ [NAD contains a fixed nicotinamide positive charge; thus, the "neutral mass" of NAD corresponds to a zwitterion including one deprotonated site; see Figure 


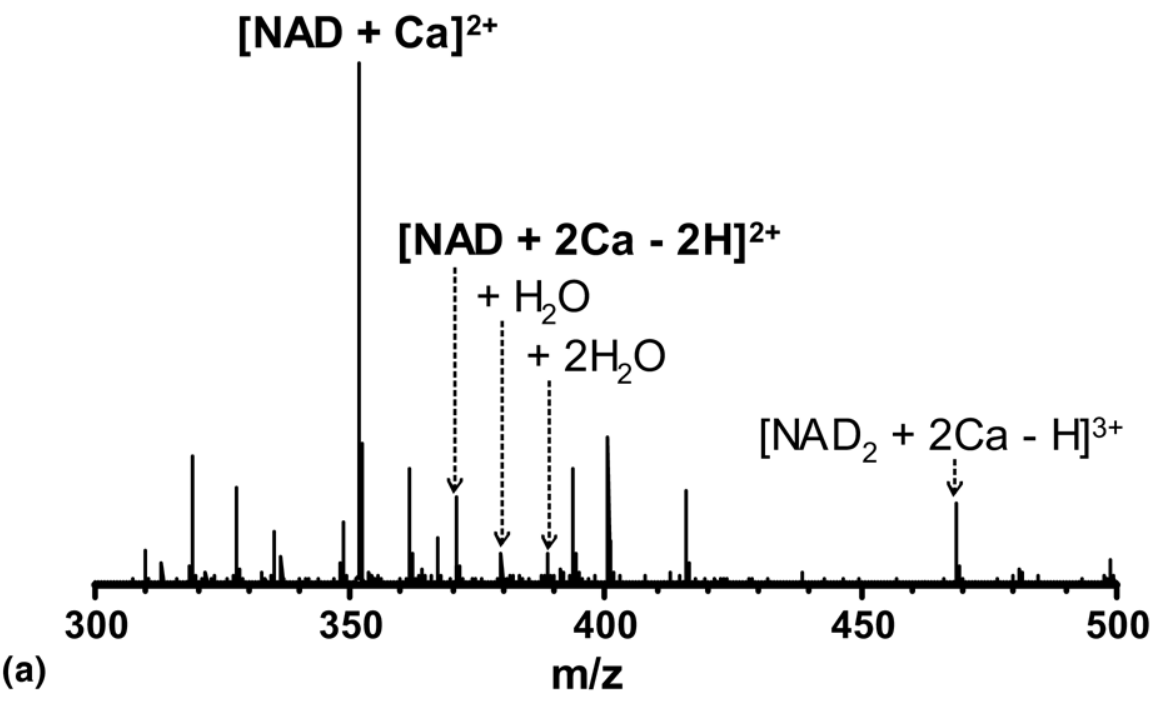

(a)

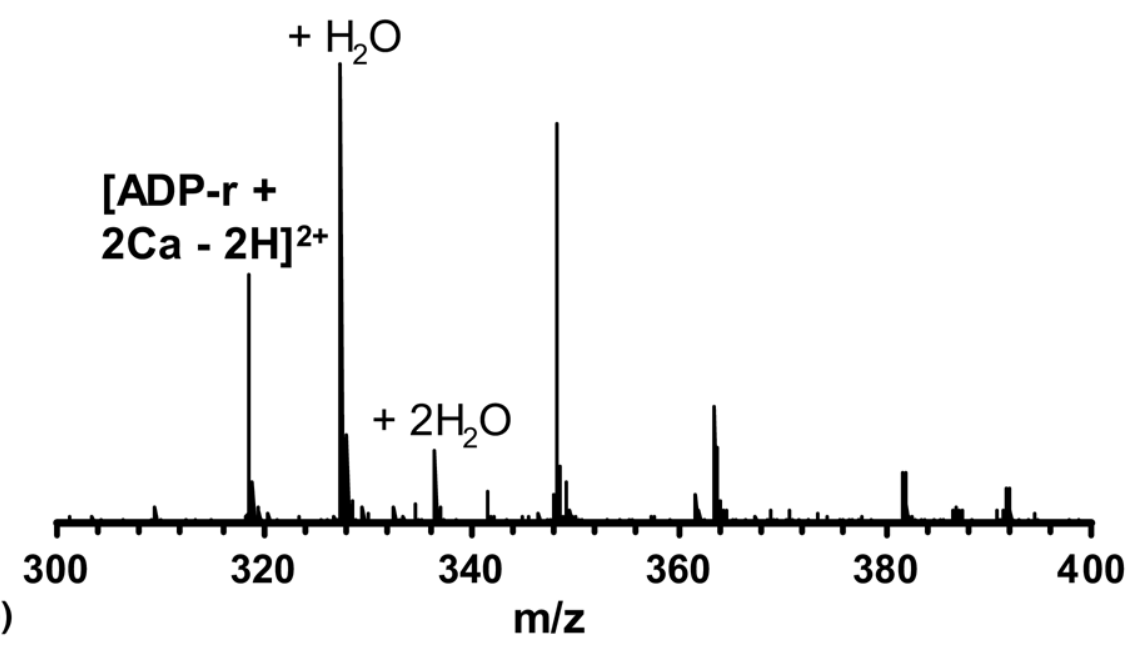

(b)

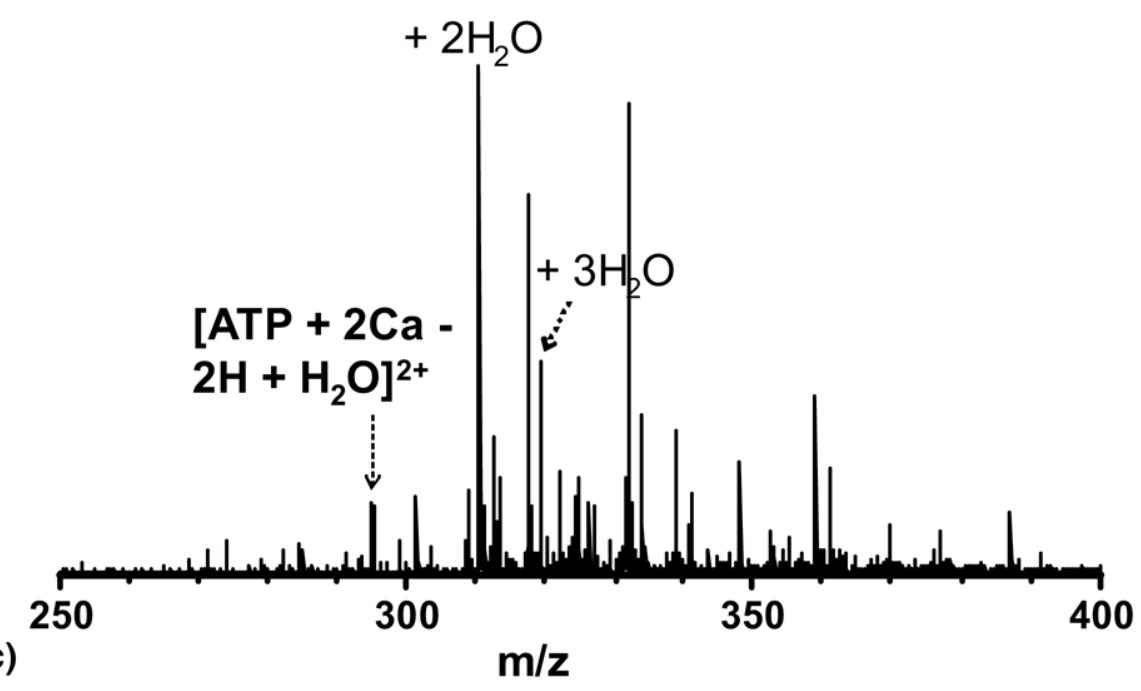

Figure 1. ESI MS of 1-5 $\mu \mathrm{M}$ NAD (a), ADP-r (b), and ATP (c) in the presence of $10-20 \mu \mathrm{M} \mathrm{Ca}^{2+}$. Unlabeled peaks are unidentified and may correspond to solvent clusters or contaminants.

2 (either phosphate group can be deprotonated, although only one is indicated in this diagram)]. Doubly charged 1:2 and triply charged 2:2 complexes ([NAD +
$2 \mathrm{Ca}-2 \mathrm{H}]^{2+}$ and $\left[\mathrm{NAD}_{2}+2 \mathrm{Ca}-\mathrm{H}\right]^{3+}$, respectively) with lower abundance were also produced in ESI of NAD. The 1:2 complex was observed in two hydrated 


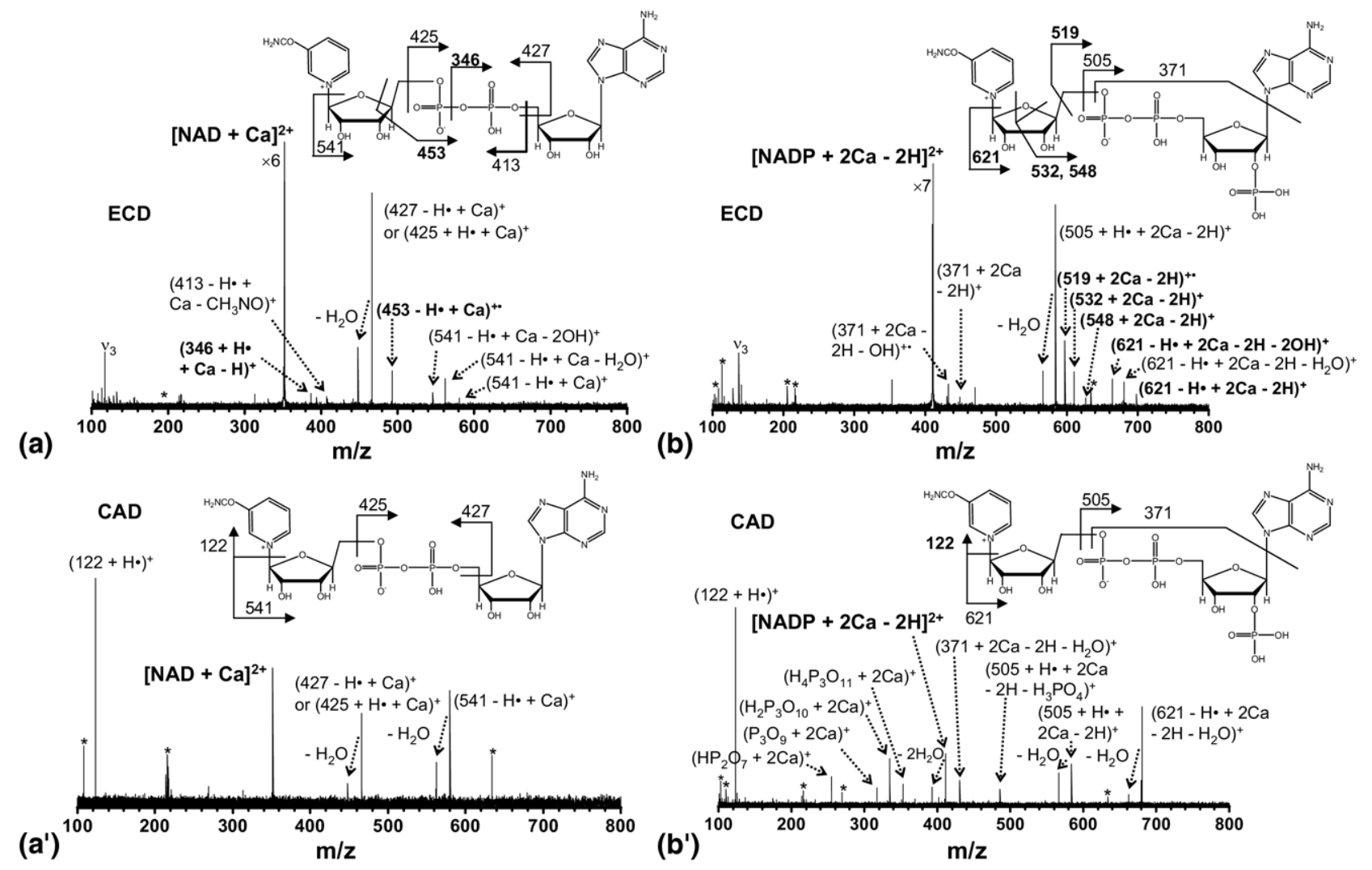

Figure 2. ECD and SORI-CAD MS /MS of $[\mathrm{NAD}+\mathrm{Ca}]^{2+}\left(\mathbf{a}\right.$ and $\left.\mathbf{a}^{\prime}\right)$ and $[\mathrm{NADP}+2 \mathrm{Ca}-2 \mathrm{H}]^{2+}(\mathbf{b}$ and $\mathbf{b}^{\prime}$ ). Electronic noise is labeled with asterisks. $\nu_{3}=$ third harmonic. Insets show structures with MS/MS bond cleavages. Product ions highlighted in bold were unique to ECD MS/MS.

forms (labeled with " $+\mathrm{H}_{2} \mathrm{O}$ " and " $+2 \mathrm{H}_{2} \mathrm{O}$ " in Figure $1 \mathrm{a})$, corresponding to addition of one and two water molecules, respectively, to the complex. For NADP (data not shown), the most abundant species was the 1:2 complex, [NADP $+2 \mathrm{Ca}-2 \mathrm{H}]^{2+}$, indicating that the additional phosphate group in NADP may be involved in binding the additional $\mathrm{Ca}^{2+}$.

Interestingly, singly and doubly hydrated 1:2 complexes constitute the most abundant species in ESI MS of ADP-r and ATP, respectively, from $\mathrm{Ca}^{2+}$-containing solutions (Figure $1 b$ and c). For ADP-r (Figure $1 b$ ), the singly hydrated 1:2 complex ([ADP-r $+2 \mathrm{Ca}-2 \mathrm{H}+$ $\mathrm{H}_{2} \mathrm{O}^{2+}$ ) is about twice as abundant as the corresponding nonhydrated precursor ion, although the relative abundance of these two species is influenced by the pressure of the nebulizing gas. For ATP (Figure 1c), nonhydrated precursor ions were not produced in ESI. Instead, precursor complexes carrying up to three $\mathrm{H}_{2} \mathrm{O}$ molecules are observed (Figure 1b).

The enhanced hydration of $\mathrm{Ca}^{2+}$-adducted ADP-r and ATP compared to $\mathrm{Ca}^{2+}$-adducted NAD may be due to structural differences of these three phosphate-containing metabolites, perhaps related to the zwitterionic nature of NAD, although it cannot be excluded that Ca-adducted ADP-r and ATP are also zwitterions [56]. Overall, the results from positivemode ESI MS show that calcium complexation can enhance the ionization of highly acidic phosphatecontaining metabolites (e.g., ATP) and facilitate detection of their $2+$ precursors, as previously found for other acidic molecules, including sulfated peptides [36], oligosaccharides [37], and sulfated oligosaccharides [57]. Detection of $2+$ precursor ions is essential for utilization of ECD.

\section{ECD and SORI-CAD MS/MS of NAD and NADP Complexed with $\mathrm{Ca}^{2+}$}

Figure 2 shows the product ion spectra resulting from ECD and SORI-CAD of NAD and NADP complexed with one and two $\mathrm{Ca}^{2+}$, i.e., [NAD + Ca] ${ }^{2+}$ and [NADP $+2 \mathrm{Ca}-2 \mathrm{H}]^{2+}$, respectively. It can be seen that several product ions have identical mass following ECD and SORI-CAD, respectively. For example, two fragments assigned as $\mathrm{Ca}^{2+}$-adducted products following phosphoester bond cleavage (mass $427 / 425$ ) and nicotinamide loss (mass 541), respectively, are observed in both the ECD and SORI-CAD spectra of [NAD + Ca] $]^{2+}$ (Figure 2a and $a^{\prime}$ ). The numerical value (e.g., 427/425 and 541) used in the product ion nomenclature denotes the mass of a neutral fragment resulting from homolytic cleavage of a covalent bond (which would form radical products because the precursor ions are even-electron 
species). The former of the two product ions mentioned earlier likely corresponds to $(425+\mathrm{H} \bullet+\mathrm{Ca})^{+}$, in which $\mathrm{H} \bullet$ denotes a hydrogen atom, thereby representing heterolytic bond cleavage to form even-electron products (recall that due to the zwitterionic nature of NAD, mass 425 includes a deprotonated site such that the total charge with one calcium adduct is one). This hypothesis is based on the observation of analogous product ions from NADP $\left([505+\mathrm{H} \bullet+2 \mathrm{Ca}-2 \mathrm{H}]^{+}\right.$ ions in Figure $2 b$ and $b^{\prime}$ ) and ADP-r (see following text).

For NADP, product ions observed in both ECD and SORI-CAD include the $[505+\mathrm{H} \bullet+2 \mathrm{Ca}-2 \mathrm{H}]^{+}$ion mentioned earlier, its $\mathrm{H}_{2} \mathrm{O}$-loss counterpart, and [621 $\left.\mathrm{H} \bullet+2 \mathrm{Ca}-2 \mathrm{H}-\mathrm{H}_{2} \mathrm{O}\right]^{+}$(Figure $2 \mathrm{~b}$ and $\mathrm{b}^{\prime}$ ). The latter ion corresponds to a combination of nicotinamide and water loss.

As can be seen in Figure 2, there are also differences observed between the ECD and SORI-CAD spectra for NAD and NADP. These differences include: (1) For both NAD and NADP, SORI-CAD produced (122+ $\mathrm{H} \bullet)^{+}$, assigned to nicotinamide, as the dominant product ion (Figure $2 \mathrm{a}^{\prime}$ and $\mathrm{b}^{\prime}$ ). This ion is complementary to the product ions based on mass 541 for NAD and mass 621 for NADP (Figure 2b and $\left.b^{\prime}\right)$. However, (122+ $\mathrm{H} \bullet)^{+}$is absent in ECD of both calcium-adducted NAD and NADP (Figure 2a and b), although complementary product ions are observed. The most abundant products found from ECD of NAD and NADP correspond to phosphoester bond cleavage (mass 425 and 505, respectively). (2) Several unique product ions are observed in ECD of NAD and NADP. Specifically, [346 + H• + Ca $-\mathrm{H}]^{+}$and $[453-\mathrm{H} \bullet+\mathrm{Ca}]^{+\bullet}$ ions are exclusively observed in ECD of NAD (Figure 2a), whereas [519+ $2 \mathrm{Ca}-2 \mathrm{H}]^{+},[532+2 \mathrm{Ca}-2 \mathrm{H}]^{+},[548+2 \mathrm{Ca}-2 \mathrm{H}]^{+}$, $[621-\mathrm{H} \bullet+2 \mathrm{Ca}-2 \mathrm{H}-2 \mathrm{OH}]^{+}$, and $[621-\mathrm{H} \bullet+2 \mathrm{Ca}$ $-2 \mathrm{H}]^{+}$ions are unique to ECD of NADP (Figure $2 b$ ). Interestingly, several of these unique ECD fragments correspond to cross-ring fragmentation of the ribose moiety linked to nicotinamide and to phosphoanhydride bond cleavage. We previously observed an increased prevalence of phosphoanhydride bond cleavage in both IRMPD and EID of NAD and nicotinic acid adenine dinucleotide phosphate (NAADP) anions compared to CAD [35]. The presence of unique product ions in ECD is highly useful for structural analysis of phosphate-containing metabolites in positive-ion mode.

Unique product ions were also seen in SORI-CAD of NADP complexed with $\mathrm{Ca}^{2+}$ (Figure $\left.2 \mathrm{~b}^{\prime}\right)$, including a series of $\mathrm{Ca}^{2+}$-phosphate species $\left(\left[\mathrm{H}_{\mathrm{x}} \mathrm{P}_{\mathrm{y}} \mathrm{O}_{\mathrm{z}}+2 \mathrm{Ca}\right]^{+} ; \mathrm{x}=\right.$ $0-4, y=2$ or $3, z=7-11)$, and a $[505+\mathrm{H} \bullet+2 \mathrm{Ca}-2 \mathrm{H}$ $\left.-\mathrm{H}_{3} \mathrm{PO}_{4}\right]^{+}$ion. The fragmentation efficiency in SORICAD is, as expected, higher (22\% for NAD and $40 \%$ for NADP under the conditions used) than that in ECD (11\% for NAD and $12 \%$ for NADP). Efficiencies were calculated based on the total product ion abundance divided by the initial precursor ion abundance (measured in a separate experiment), as proposed by McFarland et al. [58].

\section{ECD and SORI-CAD MS/MS of ADP-r Complexed with $\mathrm{Ca}^{2+}$}

The product ion spectra resulting from ECD and SORI-CAD of ADP-r complexed with $\mathrm{Ca}^{2+}$ ([ADP-r + $2 \mathrm{Ca}-2 \mathrm{H}]^{2+}$ ) are shown in Figure 3. It can be seen that the most abundant product ion produced in SORI-CAD of [ADP-r $+2 \mathrm{Ca}-2 \mathrm{H}]^{2+}$ is protonated adenine $\left([\mathrm{A}+\mathrm{H}]^{+}\right.$; see Figure $\left.3 \mathrm{~b}\right)$. Two abundant $\mathrm{Ca}^{2+}$-phosphate species, i.e., $\left[\mathrm{PO}_{4}+2 \mathrm{Ca}\right]^{+}$and $\left[\mathrm{P}_{2} \mathrm{O}_{7} \mathrm{H}+2 \mathrm{Ca}\right]^{+}$, are also observed. The presence of abundant $[\mathrm{A}+\mathrm{H}]^{+}$following SORI-CAD of ADP-r suggests that a mobile proton is present, that is, the precursor ion $[\mathrm{ADP}-\mathrm{r}+2 \mathrm{Ca}-2 \mathrm{H}]^{2+}$ may contain three deprotonated and one protonated site. Ionexchange chromatography has suggested that, for glycosides, C-3 hydroxyl hydrogens are acidic [59]. Thus, the $\mathrm{C}-3 \mathrm{OH}$ group of either ribose may constitute the third deprotonation site. In comparison, [A + $\mathrm{H}^{+}$and $\mathrm{Ca}^{2+}$-phosphate species are of low abdundance in ECD of ADP-r (Figure 3a). A [249 + H• + $2 \mathrm{Ca}-3 \mathrm{H}]^{+}$ion is the dominant fragment in ECD of ADP-r. This fragment and its $\mathrm{CH}_{2} \mathrm{O}$-loss counterpart, $[219+\mathrm{H} \bullet+2 \mathrm{Ca}-3 \mathrm{H}]^{+}$, which correspond to combined cleavage of a phosphoester bond and crossring fragmentation of one of the ribose moieties, are observed in both ECD and SORI-CAD. The observation of neutral loss of a mass corresponding to three formaldehyde molecules from the charge-reduced 1+ precursor ions, and from the $2+$ precursors in ECD and SORI-CAD, respectively, suggests that the crossring fragmentation related to mass 249 and 219 occurred within the free-end ribose moiety because the complementary product would be $\left(\mathrm{CH}_{2} \mathrm{O}\right)_{3}$. One additional low-abundance product ion, [293- $\mathrm{H} \bullet+$ $2 \mathrm{Ca}-3 \mathrm{H}]^{+}$, is also observed in both SORI-CAD and ECD. This product corresponds to cleavage of a phosphoanhydride bond.

In addition to the product ions discussed earlier that are common to ECD and SORI-CAD, unique fragmentation was observed in ECD of ADP-r (Figure 3a), similar to ECD of NAD and NADP (Figure 2). Unique ECD fragments are $[354+2 \mathrm{H} \bullet+2 \mathrm{Ca}-2 \mathrm{H}]^{+}$and $[426$ $+\mathrm{H} \bullet+2 \mathrm{Ca}-3 \mathrm{H}]^{+}$. The latter product ion was also observed in ECD of NAD (Figure 2a, labeled " 425 " due to the zwitterionic nature of NAD) and an analogous product (related to mass 505) was also observed in ECD of NADP (Figure $2 \mathrm{~b}$ ). The $[354+2 \mathrm{H} \bullet+2 \mathrm{Ca}-2 \mathrm{H}]^{+}$ product ion is associated with cross-ring fragmentation of the adenosine ribose moiety. Such fragmentation was not observed in ECD of NAD and NADP (Figure 2) and could possibly be a result of structural differences due to the deprotonation of the $\mathrm{C}-3$ ribose carbon discussed earlier. As for NAD and NADP, additional structural information about ADP-r is obtained with ECD compared to that obtained with SORI-CAD. The fragmentation efficiency in SORI-CAD of ADP-r was 38\% and that in ECD was $22 \%$. 

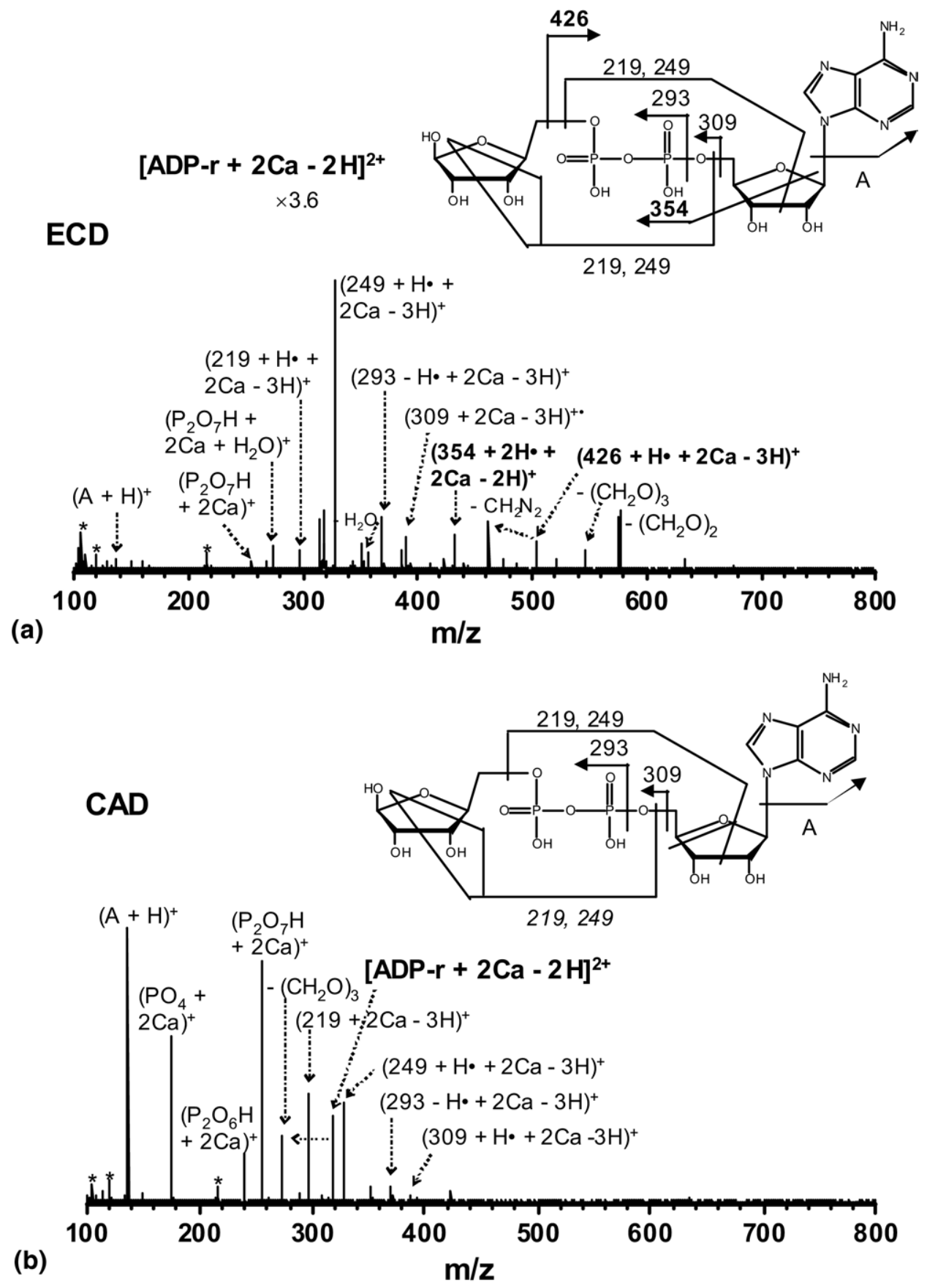

Figure 3. ECD (a) and SORI-CAD (b) MS/MS of $[\mathrm{ADP}-\mathrm{r}+2 \mathrm{Ca}-2 \mathrm{H}]^{2+}$. Electronic noise is labeled with asterisks. Insets show the structure and MS/MS bond cleavages. Product ions highlighted in bold were unique to ECD MS/MS.

ECD and SORI-CAD of Hydrated ADP-r, ATP, and GTP Complexed with $\mathrm{Ca}^{2+}$

Figure 4 shows the product ion spectra resulting from ECD and SORI-CAD of singly and doubly hydrated ADP-r complexed with $\mathrm{Ca}^{2+}$. Compared to the case of nonhydrated ADP-r (Figure 3), addition of one water molecule does not greatly affect the fragmentation behavior of the 2:1 $\mathrm{Ca}^{2+}$-ADP-r complex, neither in ECD, nor in SORI-CAD (Figure $4 a$ and $a^{\prime}$, respectively) except that loss of $\mathrm{H}_{2} \mathrm{O}$ constitutes the dominant fragmentation process in SORI-CAD (Figure 4a'). However, less extensive fragmentation is seen in ECD and SORICAD MS/MS of the doubly hydrated 2:1 $\mathrm{Ca}^{2+}$-ADP-r complex (Figure $4 b$ and $b^{\prime}$ ). Two structural fragments, $[249+\mathrm{H} \bullet+2 \mathrm{Ca}-3 \mathrm{H}]^{+}$and $[309+2 \mathrm{Ca}-3 \mathrm{H}]^{+\bullet}$, were observed in ECD MS/MS of doubly hydrated $\mathrm{Ca}^{2+}$-adducted ADP-r (Figure $4 \mathrm{~b}$ ) and three were found following SORI-CAD MS/MS, [219+ H• +2Ca - 
(a)

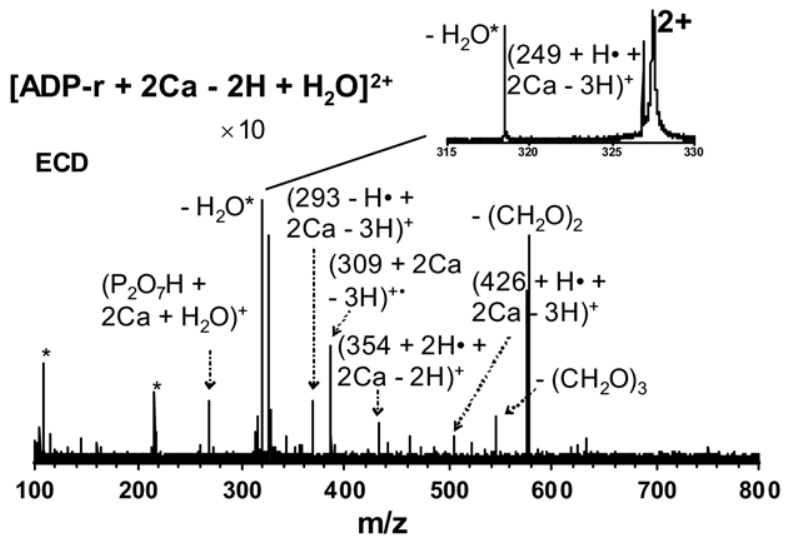

(b)

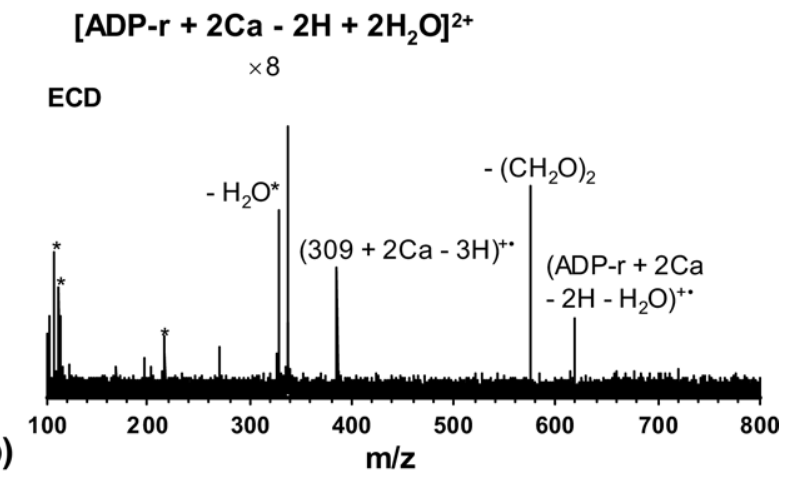

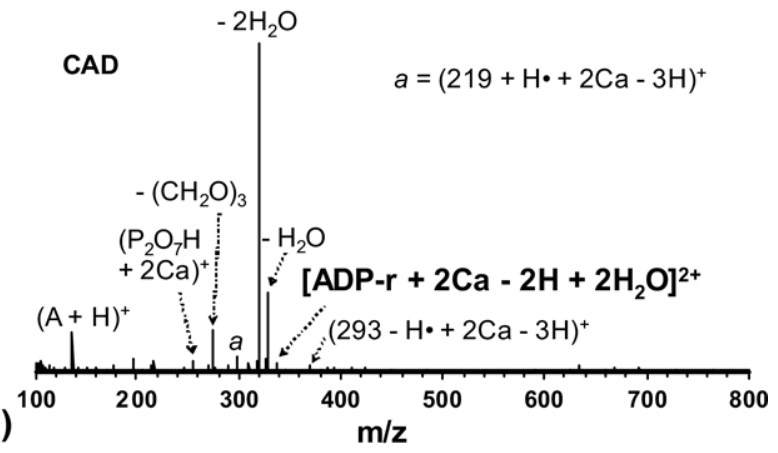

Figure 4. ECD and SORI-CAD MS/MS of singly (a and $\mathbf{a}^{\prime}$ ) and doubly ( $\mathbf{b}$ and $\mathbf{b}^{\prime}$ ) hydrated [ADP-r $+2 \mathrm{Ca}-2 \mathrm{H}^{2+}$, respectively. Electronic noise and $\mathrm{H}_{2} \mathrm{O}$-loss product ions present before electron irradiation (as a result of vibrational excitation) are labeled with asterisks. The inset in (a) shows an expanded view of the region from $\mathrm{m} / \mathrm{z} 315-330$.

$3 \mathrm{H}]^{+},[293-\mathrm{H} \bullet+2 \mathrm{Ca}-3 \mathrm{H}]^{+}$, and protonated adenine (Figure $4 b^{\prime}$ ). The unique product ions related to mass 354 and 426 observed in ECD of non- and singly hydrated ADP-r (Figures 3a and 4a) were not observed in ECD of doubly hydrated ADP-r. The ECD fragmentation efficiency was lower for hydrated ADP-r ( $8 \%$ for the singly hydrated species and $6 \%$ for the doubly hydrated species) compared to unsolvated ADP-r $(22 \%)$. This behavior may be due to a decreased electron capture cross section for the water-coordinated metal complex.

ECD and SORI-CAD MS/MS of doubly hydrated ATP and GTP complexed with $\mathrm{Ca}^{2+}$ are shown in Figure 5. As discussed earlier, nonhydrated species were not observed for these molecules and doubly hydrated complexes constituted the most abundant precursor ions. Unsurprisingly, loss of two water molecules from the $2+$ precursor ions is the dominant fragmentation process in SORI-CAD of both doubly hydrated calcium-adducted ATP and GTP (Figure 5a' and $\left.b^{\prime}\right)$. Abundant loss of two $\mathrm{H}_{2} \mathrm{O}$ is also seen from the charge-reduced $1+$ precursor ions in ECD of both doubly hydrated ATP and GTP. For the latter complex, a $\left[373+2 \mathrm{Ca}-3 \mathrm{H}+\mathrm{H}_{2} \mathrm{O}\right]^{+}$product ion is slightly more abundant than the double $\mathrm{H}_{2} \mathrm{O}$ losses (Figure 5a). This product ion corresponds to neutral adenine loss with retention of one water molecule. An analogous product ion corresponding to neutral loss of guanine but with retention of both water molecules is observed at lower abundance in ECD of the GTP complex (Figure $5 b)$. Interestingly, these product ions are also observed in SORI-CAD of both the ATP and the GTP complex, demonstrating that neutral base loss is a very low energy fragmentation pathway, comparable to dissociation of the noncovalent interactions in these complexes. The fact that guanine loss can occur without loss of either water molecule suggests that this pathway requires less activation energy than adenine loss, consistent with the nucleic acid MS/MS literature, which contains ample evidence of guanine as the most labile nucleobase in both ECD [45, 60, 61] and CAD [62].

Other $\mathrm{H}_{2} \mathrm{O}$-containing product ions include [257 + $\left.\mathrm{H} \bullet+2 \mathrm{Ca}-3 \mathrm{H}+\mathrm{H}_{2} \mathrm{O}\right]^{+}$from SORI-CAD and ECD of the ATP complex, and from ECD of the GTP complex (Figure $5 \mathrm{a}, \mathrm{a}^{\prime}$, and $\mathrm{b}$ ), and $[360-\mathrm{H} \bullet+2 \mathrm{Ca}-3 \mathrm{H}+$ $2 \mathrm{H}_{2} \mathrm{O}^{+}{ }^{\bullet}$ from ECD of the GTP complex (Figure 5b). The former ion corresponds to phosphoester bond cleavage combined with loss of one water molecule and the latter ion corresponds to cross-ring fragmentation within the ribose moiety without loss of either water molecule. Because the latter type of fragmentation is a highenergy fragmentation process [63-66], the observation of this product ion may be another testament to the soft, possibly non-ergodic, nature of ECD [29, 67-69]. Phos- 


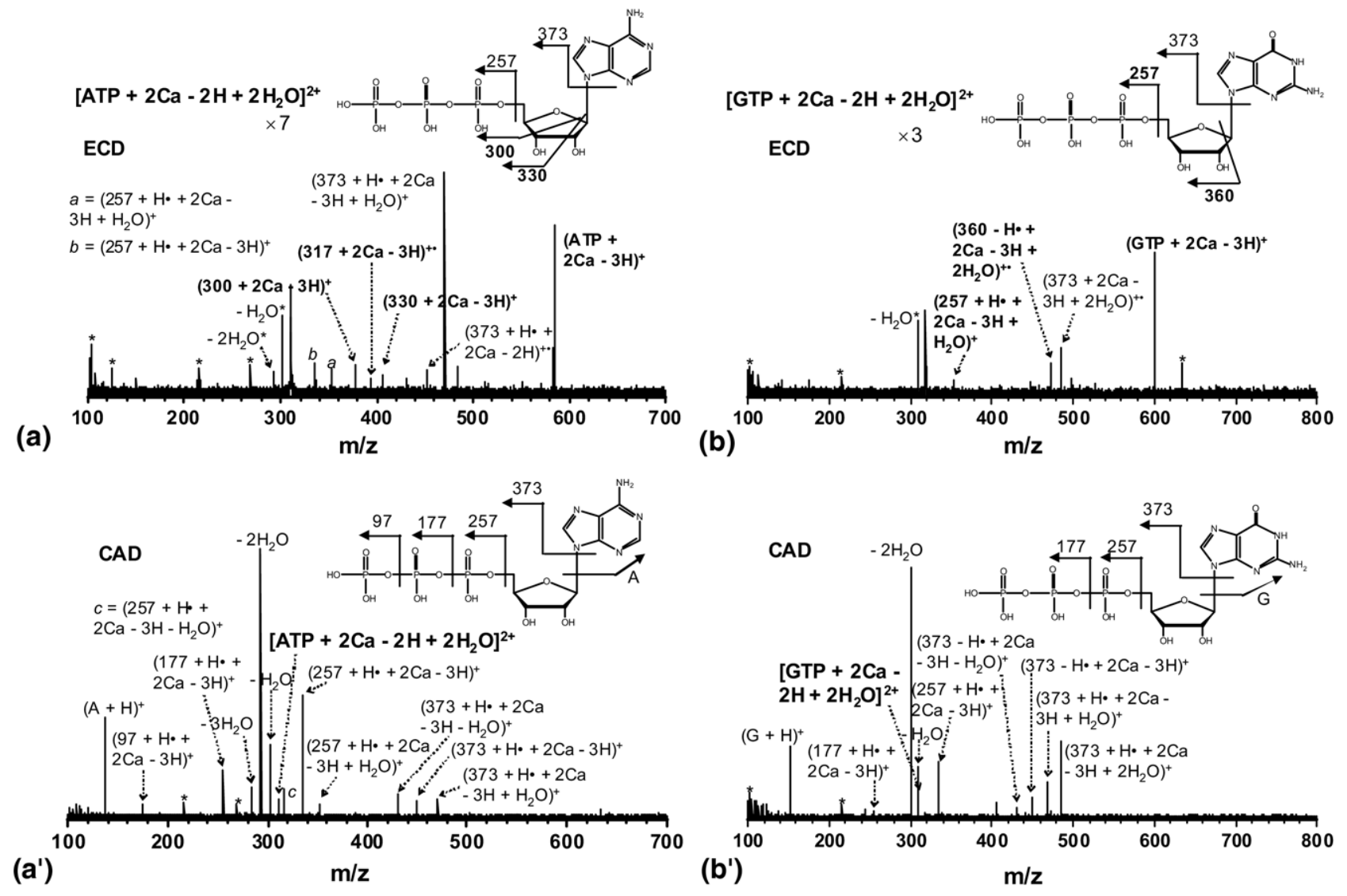

Figure 5. ECD and SORI-CAD MS /MS of $\left[\mathrm{ATP}+2 \mathrm{Ca}-2 \mathrm{H}+2 \mathrm{H}_{2} \mathrm{O}\right]^{2+}\left(\mathbf{a}\right.$ and $\left.\mathbf{a}^{\prime}\right)$ and $[\mathrm{GTP}+2 \mathrm{Ca}$ $\left.-2 \mathrm{H}+2 \mathrm{H}_{2} \mathrm{O}\right]^{2+}\left(\mathbf{b}\right.$ and $\left.\mathbf{b}^{\prime}\right)$. Electronic noise and $\mathrm{H}_{2} \mathrm{O}$-loss product ions present before electron irradiation (as a result of vibrational excitation) are labeled with asterisks. Insets show structures and MS/MS bond cleavages. Fragmentation highlighted in bold was uniquely to ECD MS/MS.

phoester bonds are labile in CAD MS/MS. For example, preferential phosphate loss is seen in CAD of phosphopeptides [70-72]. The ECD fragmentation efficiency of doubly hydrated ATP was the same as that of non-hydrated ADP-r (22\%). By contrast, the ECD fragmentation efficiency for doubly hydrated GTP was only $8 \%$. This reduced efficiency may be due to more complete metal coordination in the GTP complex, which could possibly also explain the "softer" nature of the GTP ECD fragmentation pattern (i.e., all product ions retain water).

In addition to the intriguing doubly hydrated crossring fragment mentioned earlier for the GTP complex, unique cross-ring fragmentation without retention of water was also seen in ECD MS/MS of the ATP complex (Figure 5a, product ions related to masses 300 and 330). Cross-ring fragmentation is generally of low occurrence in carbohydrate MS/MS; however, we have recently shown that ECD of metal-adducted oligosaccharides displays enhanced, sometimes dominant, cross-ring cleavage [37]. Such fragmentation provides valuable information regarding sugar linkage. Unique product ions were also observed in SORI-CAD, including $\mathrm{Ca}^{2+}$-adducted phosphate species (related to mass 97 and 177, Figure $5 a^{\prime}$ and $b^{\prime}$ ) providing information about the number of phosphate groups. Thus, as previously demonstrated for a range of biomolecules [4548], ECD and SORI-CAD provide complementary structural information about metabolite cations.

\section{Conclusion}

We have shown that calcium complexation facilitates detection of $2+$ precursor ions for acidic phosphatecontaining metabolites in ESI MS. Hydration of the 2+ precursor ions was found to be minor for NAD and NADP, whereas it was dominant in ESI MS of ADP-r, ATP, and GTP. In fact, nonhydrated 2+ precursor ions were not observed in ESI MS of ATP and GTP in the presence of calcium. ECD and SORI-CAD MS/MS of these $\mathrm{Ca}^{2+}$-phosphate-containing metabolite complexes showed complementary fragmentation pathways. Unique fragmentation was observed in both ECD and SORI-CAD MS/MS. In particular, cross-ring fragmentation within the ribose moiety was observed only in ECD. Intriguingly, a doubly hydrated cross-ring fragment was observed in ECD of a doubly hydrated 2:1 $\mathrm{Ca}^{2+}$-GTP complex, providing another testament to the soft nature of ECD. Unique product ions observed in SORI-CAD MS/MS mostly corresponded to $\mathrm{Ca}^{2+}$-phos- 
phate species, which are less valuable for metabolite structural analysis. Observed fragmentation pathways in both ECD and SORI-CAD differed for different phosphate-containing metabolites. For example, the presence of nicotinamide in NAD and NADP appeared to influence the fragmentation behavior. Guanine loss appeared to require less activation energy than adenine loss, consistent with the nucleic acid MS/MS literature. From these results, we conclude that a combination of calcium complexation and ECD is a useful approach for generating additional structural information about acidic metabolites compared to CAD MS/MS. Off-line nano-LC should allow improved sensitivity beyond the $\mu \mathrm{M}$ range investigated here.

\section{Acknowledgments}

This work was supported by the Searle Scholars Program, a Dow Corning Assistant Professorship, and the University of Michigan. $\mathrm{KH}$ is immensely grateful to Roman Zubarev for a warm welcome and enthusiastic and authoritative introduction to graduate studies as well as for giving us EЦD and all the related acronyms that keep us busy in the lab and make for wonderful new discoveries. Spasibo!

\section{References}

1. Stephanopoulos, G.; Alper, H.; Moxley, J. Exploiting Biological Complexity for Strain Improvement through Systems Biology. Nat. Biotechnol. 2004, 22, 1261-1267.

2. Wendisch, V. F.; Bott, M.; Kalinowski, J.; Oldiges, M.; Wiechert, W. Emerging Corynebacterium Glutamicum Systems Biology. J. Biotechnol. 2006, 124, 74-92.

3. Cascante, M.; Boros, L. G.; Comin-Anduix, B.; de Atauri, P.; Centelles, J. J.; Lee, P. W. Metabolic Control Analysis in Drug Discovery and Disease. Nat. Biotechnol. 2002, 20, 243-249.

4. Kell, D. B. Metabolomics and Systems Biology: Making Sense of the Soup. Curr. Opin. Microbiol. 2004, 7, 296-307.

5. Lindon, J. C.; Holmes, E.; Bollard, M. E.; Stanley, E. G.; Nicholson, J. K. Metabonomics Technologies and Their Applications in Physiological Monitoring, Drug Safety Assessment and Disease Diagnosis. Biomarkers 2004, 9, 1-31.

6. Rochfort, S. Metabolomics Reviewed: A New "Omics" Platform Technology for Systems Biology and Implications for Natural Products Research. J. Nat. Prod. 2005, 68, 1813-1820.

7. van der Greef, J.; Stroobant, P.; van der Heijden, R. The Role of Analytical Sciences in Medical Systems Biology. Curr. Opin. Chem. Biol. 2004, 8, 559-565.

8. Villas-Boas, S. G.; Mas, S.; Akesson, M.; Smedsgaard, J.; Nielsen, J. Mass Spectrometry in Metabolome Analysis. Mass Spectrom. Rev. 2005, 24, 613-646.

9. Dunn, W. B.; Ellis, D. I. Metabolomics: Current Analytical Platforms and Methologies. Trends Anal. Chem. 2005, 24, 285-294.

10. Lenz, E. M.; Bright, J.; Knight, R.; Wilson, I. D.; Major, H. Cyclosporin A-Induced Changes in Endogenous Metabolites in Rat Urine: A Metabonomic Investigation Using High Field 1H NMR Spectroscopy, HPLCTOF/MS and Chemometrics. J. Pharm. Biomed. Anal. 2004, 35, 599-608.

11. Boskey, A. L.; Mendelsohn, R. Infrared Spectroscopic Characterization of Mineralized Tissues. Vib. Spectrosc. 2005, 38, 107-114

12. Defernez, M.; Colquhoun, I. J. Factors Affecting the Robustness of Metabolite Fingerprinting Using 1H NMR Spectra. Phytochemistry 2003, 62, 1009-1017.

13. Deleris, G.; Petibois, C. Applications of FT-IR Spectrometry to Plasma Contents. Vib. Spectrosc. 2003, 32, 129-136.

14. Brown, S. C.; Kruppa, G.; Dasseux, J. L. Metabolomics Applications of FT-ICR Mass Spectrometry. Mass Spectrom. Rev. 2005, 24, 223-231.

15. Metz, T. D.; Zhang, L.; Page, J. S.; Shen, Y.; Callister, S. J.; Jacobs, J. M.; Smith, R. D. Future of Liquid Chromatography-Mass Spectrometry in Metabolic Profiling and Metabolomic Studies for Biomarker Discovery. Biomarkers Med. 2007, 1, 159-185.

16. Want, E. J.; Cravatt, B. F.; Siuzdak, G. The Expanding Role of Mass Spectrometry in Metabolite Profiling and Characterization. Chem. Biochem. 2005, 6, 1941-1951.

17. Bajad, S. U.; Lu, W.; Kimball, E. H.; Yuan, J.; Peterson, C.; Rabinowitz, J. D. Separation and Quantitation of Water Soluble Cellular Metabolites by Hydrophilic Interaction Chromatography-Tandem Mass Spectrometry. J. Chromatogr. A 2006, 1125, 76-88.
18. Edwards, J. L.; Chisolm, C. N.; Shackman, J. G.; Kennedy, R. T. Negative Mode Sheatless Capillary Electrophoresis Electrospray Ionization-Mass Spectrometry for Metabolite Analysis of Prokaryotes. J. Chromatogr. A 2006, 1106, 80-88.

19. Luo, B.; Groenke, K.; Takors, R.; Wandrey, C.; Oldiges, M. Simultaneous Determination of Multiple Intracellular Metabolites in Glycolysis, Pentose Phosphate Pathway and Tricarboxylic Acid Cycle by Liquid Chromatography-Mass Spectrometry. J. Chromatogr. A 2007, 1147, 153 164.

20. Huck, J. H.; Struys, E. A.; Verhoeven, N. M.; Jakobs, C.; van der Knaap, M. S. Profiling of Pentose Phosphate Pathway Intermediates in Blood Spots by Tandem Mass Spectrometry: Application to Transaldolase Deficiency. Clin. Chem. 2003, 49, 1375-1380.

21. Lu, W.; Kimball, E.; Rabinowitz, J. D. A High-Performance Liquid Chromatography-Tandem Mass Spectrometry Method for Quantitation of Nitrogen-Containing Intracellular Metabolites. J. Am. Soc. Mass Spectrom. 2006, 17, 37-50.

22. Buchholz, A.; Takors, R.; Wandrey, C. Quantification of Intracellular Metabolites in Escherichia coli K12 Using Liquid ChromatographicElectrospray Ionization Tandem Mass Spectrometric Techniques. Anal. Biochem. 2001, 295, 129-137.

23. Feurle, J.; Jomaa, H.; Wilhelm, M.; Gutsche, B.; Herderich, M. Analysis of Phosphorylated Carbohydrates by High-Performance Liquid Chromatography-Electrospray Ionization Tandem Mass Spectrometry Utilising a Beta-Cyclodextrin Bonded Stationary Phase. J. Chromatogr. A 1998, $803,111-119$

24. Sekiguchi, Y.; Mitsuhashi, N.; Kokaji, Y.; Miyakoda, H.; Mimura, T. Development of a Comprehensive Analytical Method for Phosphate Metabolites in Plants by Ion Chromatography Coupled with Tandem Mass Spectrometry. J. Chromatogr. A 2005, 1085, 131-136.

25. Sun, G.; Yang, K.; Zhao, Z.; Guan, S.; Han, X.; Gross, R. W. Shotgun Metabolomics Approach for the Analysis of Negatively Charged WaterSoluble Cellular Metabolites from Mouse Heart Tissue. Anal. Chem. 2007, 79, 6629-6640.

26. Wysocki, V. H.; Tsaprailis, G.; Smith, L. L.; Breci, L. A. Mobile and Localized Protons: A Framework for Understanding Peptide Dissociation. J. Mass Spectrom. 2000, 35, 1399-1406.

27. Aharoni, A.; Ric. de Vos, C. H.; Verhoeven, H. A.; Maliepaard, C. A.; Kruppa, G.; Bino, R.; Goodenowe, D. B. Nontargeted Metabolome Analysis by Use of Fourier Transform Ion Cyclotron Mass Spectrometry. OMICS 2002, 6, 217-234.

28. Zubarev, R. A.; Horn, D. M.; Fridriksson, E. K.; Kelleher, N. L.; Kruger N. A.; Lewis, M. A.; Carpenter, B. K.; McLafferty, F. W. Electron Capture Dissociation for Structural Characterization of Multiply Charged Protein Cations. Anal. Chem. 2000, 72, 563-573.

29. Zubarev, R. A.; Kellerher, N. L.; McLafferty, F. W. Electron Capture Dissociation of Multiply Charged Protein Cations. A Nonergodic Process. J. Am. Chem. Soc. 1998, 120, 3265-3266.

30. Budnik, B. A.; Haselmann, K. F.; Elkin, Y. N.; Gorbach, V. I.; Zubarev, R. A. Applications of Electron-Ion Dissociation Reactions for Analysis of Polycationic Chitooligosaccharides in Fourier Transform Mass Spectrometry. Anal. Chem. 2003, 75, 5994-6001.

31. Cody, R. B.; Freiser, B. S. Electron Impact Excitation of Ions from Organics: An Alternative to Collision Induced Dissociation. Anal. Chem. 1979, 51, 541-551.

32. Lioe, H.; O'Hair, R. A. Comparison of Collision-Induced Dissociation and Electron-Induced Dissociation of Singly Protonated Aromatic Amino Acids, Cystine and Related Simple Peptides Using a Hybrid Linear Ion Trap-FT-ICR Mass Spectrometer. Anal. Bioanal. Chem. 2007, 389, 1429-1437.

33. Little, D. P.; Speir, J. P.; Senko, M. W.; O'Connor, P. B.; McLafferty, F. W. Infrared Multiphoton Dissociation of Large Multiply Charged Ions for Biomolecule Sequencing. Anal. Chem. 1994, 66, 2809-2815.

34. Woodin, R. L.; Bomse, D. S.; Beauchamp, J. L. Multiphoton Dissociation of Molecules with Low Power Continuous Wave Infrared Laser Radiation. J. Am. Chem. Soc. 1978, 100, 3248-3250.

35. Yoo, H. J.; Liu, H.; Håkansson, K. Infrared Multiphoton Dissociation and Electron-Induced Dissociation as Alternative MS/MS Strategies for Metabolite Identification. Anal. Chem. 2007, 20, 7858-7866.

36. Liu, H.; Håkansson, K. Electron Capture Dissociation of Tyrosine O-Sulfated Peptides Complexed with Divalent Metal Cations. Anal. Chem. 2006, 78, 7570-7576.

37. Adamson, J. T.; Håkansson, K. Electron Capture Dissociation of Oligosaccharides Ionized with Alkali, Alkaline Earth, and Transition Metals. Anal. Chem. 2007, 79, 2901-2910.

38. Zubarev, R. A. Electron-Capture Dissociation Tandem Mass Spectrometry. Curr. Opin. Biotechnol. 2004, 15, 12-16.

39. Adamson, J. T.; Håkansson, K. Infrared Multiphoton Dissociation and Electron Capture Dissociation of High-Mannose Type Glycopeptides. J. Proteome Res. 2006, 5, 493-501.

40. Håkansson, K.; Chalmers, M. J.; Quinn, J. P.; McFarland, M. A. Hendrickson, C. L.; Marshall, A. G. Combined Electron Capture and Infrared Multiphoton Dissociation for Multistage MS/MS in a Fourier Transform Ion Cyclotron Resonance Mass Spectrometer. Anal. Chem. 2003, 75, 3256-3262.

41. Håkansson, K.; Cooper, H. J.; Emmett, M. R.; Costello, C. E.; Marshall A. G.; Nilsson, C. L. Electron Capture Dissociation and Infrared Multiphoton Dissociation MS/MS of an N-Glycosylated Tryptic Peptic to Yield Complementary Sequence Information. Anal. Chem. 2001, 73, $4530-4536$. 
42. Kjeldsen, F.; Haselmann, K. F.; Budnik, B. A.; Sorensen, E. S.; Zubarev, R. A. Complete Characterization of Posttranslational Modification Sites in the Bovine Milk Protein PP3 by Tandem Mass Spectrometry with Electron Capture Dissociation as the Last Stage. Anal. Chem. 2003, 75, 2355-2361.

43. Cooper, H. J ; Håkansson, K.; Marshall, A. G. The Role of Electron Capture Dissociation in Biomolecular Analysis. Mass Spectrom. Rev. 2005, 24, 201-222.

44. McLafferty, F. W.; Horn, D. M.; Breuker, K.; Ge, Y.; Lewis, M. A.; Cerda, B.; Zubarev, R. A.; Carpenter, B. K. Electron Capture Dissociation of Gaseous Multiply Charged Ions by Fourier-Transform Ion Cyclotron Resonance. J. Am. Soc. Mass Spectrom. 2001, 12, 245-249.

45. Håkansson, K.; Hudgins, R. R.; Marshall, A. G.; O'Hair, R. A. J. Electron Capture Dissociation and Infrared Multiphoton Dissociation of Oligodeoxynucleotide Dications. J. Am. Soc. Mass Spectrom. 2003, 14, 23-41.

46. Yang, J.; Håkansson, K. Fragmentation of Oligoribonucleotides from Gas-Phase Ion-Electron Reactions. J. Am. Soc. Mass Spectrom. 2006, 17, 1369-1375.

47. Kleinnijenhuis, A. J.; Duursma, M. C.; Breukink, E.; Heeren, R. M.; Heck A. J. Localization of Intramolecular Monosulfide Bridges in Lantibiotics Determined with Electron Capture Induced Dissociation. Anal. Chem. 2003, 75, 3219-3225

48. Liu, H.; Håkansson, K.; Lee, J. Y.; Sherman, D. H. Collision-Activated Dissociation, Infrared Multiphoton Dissociation, and Electron Capture Dissociation of the Bacillus Anthracis Siderophore Petrobactin and Its Metal Ion Complexes. J. Am. Soc. Mass Spectrom. 2007, 18, 842-849.

49. Gauthier, J.; Trautman, T. R.; Jacobson, D. B. Sustained Off-Resonance Irradiation for Collision-Activated Dissociation Involving Fourier Transform Mass Spectrometry. Collision-Activated Dissociation Technique That Emulates Infrared Multiphoton Dissociation. Anal. Chim. Acta 1991, 246, 211-225.

50. Yang, J.; Mo, J.; Adamson, J. T.; Håkansson, K. Characterization of Oligodeoxynucleotides by Electron Detachment Dissociation Fourier Transform Ion Cyclotron Resonance Mass Spectrometry. Anal. Chem. 2005, 77, 1876-1882

51. Belov, M. E.; Nikolaev, E. N.; Anderson, G. A.; Udseth, H. R.; Conrads, T. P.; Veenstra, T. D.; Masselon, C. D.; Gorshkov, M. V.; Smith, R. D. Design and Performance of an ESI Interface for Selective External Ion Accumulation Coupled to a Fourier Transform Ion Cyclotron Mass Spectrometer. Anal. Chem. 2001, 73, 253-261.

52. Hendrickson, C. L.; Quinn, J. P.; Emmett, M. R.; Marshall, A. G. Mass-Selective External Ion Accumulation for Fourier Transform Ion Cyclotron Resonance Mass Spectrometry. Proc. 49th ASMS Conf. Mass Spectrometry and Allied Topics, Chicago, IL, 2001, CD-ROM.

53. de Koning, L. J.; Nibbering, N. M. M.; van Orden, S. L.; Laukien, F. H. Mass Selection of Ions in a Fourier Transform Ion Cyclotron Resonance Trap Using Correlated Harmonic Excitation Fields (CHEF). Int. J. Mass Spectrom. 1997, 165, 209-219.

54. Tsybin, Y. O.; Witt, M.; Baykut, G.; Kjeldsen, F.; Håkansson, P. Combined Infrared Multiphoton Dissociation and Electron Capture Dissociation with a Hollow Electron Beam in Fourier Transform Ion Cyclotron Resonance Mass Spectrometry. Rapid Commun. Mass Spectrom. 2003, 17, 1759-1768.

55. Senko, M. W.; Canterbury, J. D.; Guan, S.; Marshall, A. G. A HighPerformance Modular Data System for Fourier Transform Ion Cyclotron Resonance Mass Spectrometry. Rapid Commun. Mass Spectrom. 1996, 10, 1839-1844.

56. Strittmatter, E. F.; Lemoff, A. S.; Williams, E. R. Structure of Cationized Glycine, Gly-M (M = Be, Mg, Ca, Sr, Ba), in the Gas Phase: Intrinsic
Effect of Cation Size on Zwitterion Stability. J. Phys. Chem. A 2000, 104, 9793-9796.

57. Liu, H.; Håkansson, K. Characterization of O-Sulfated Peptides and Oligosaccharides by Divalent Metal Complexation and Electron Capture Dissociation. Proc. 55th ASMS Conf. on Mass Spectrometry and Allied Topics, Indianapolis, IN, 2007, CD-ROM.

58. McFarland, M. A.; Chalmers, M. J.; Quinn, J. P.; Hendrickson, C. L. Marshall, A. G. Evaluation and Optimization of Electron Capture Dissociation Efficiency in Fourier Transform Ion Cyclotron Resonance Mass Spectrometry. J. Am. Soc. Mass Spectrom. 2005, 16, 1060-1066.

59. Neuberger, A.; Wilson, B. M. The Separation of Glycosides on a Strongly Basic Ion-Exchange Resin: An Interpretation in Terms of Acidity. Carbohydr. Res. 1971, 17, 89-95.

60. Olsen, J. V.; Haselmann, K. F.; Nielsen, M. L.; Budnik, B. A.; Nielsen P. E.; Zubarev, R. A. Comparison of Electron Capture Dissociation and Collisionally Activated Dissociation of Polycations of Peptide Nucleic Acids. Rapid Commun. Mass Spectrom. 2001, 15, 969-974.

61. Schultz, K. N.; Håkansson, K. Rapid Electron Capture Dissociation of Mass-Selectively Accumulated Oligodeoxynucleotide Dications. Int. J. Mass Spectrom. 2004, 234, 123-130.

62. Hannis, J. C.; Muddiman, D. C. Tailoring the Gas-Phase Dissociation and Determining the Relative Energy of Activation for Dissociation of 7-Deaza Purine Modified Oligonucleotides Containing a Repeating Motif. Int. J. Mass Spectrom. 2002, 219, 139-150.

63. Harvey, D. J.; Bateman, R. H.; Green, M. R. High-Energy CollisionInduced Fragmentation of Complex Oligosaccharides Ionized by Matrix-Assisted Laser Desorption/Ionization Mass Spectrometry. J. Mass Spectrom. 1997, 32, 167-187.

64. Harvey, D. J.; Naven, T. J.; Kuster, B.; Bateman, R. H.; Green, M. R. Critchley, G. Comparison of Fragmentation Modes for the Structural Determination of Complex Oligosaccharides Ionized by Matrix-Assisted Laser Desorption/Ionization Mass Spectrometry. Rapid Commun. Mass Spectrom. 1995, 9, 1556-1561.

65. Lemoine, J.; Strecker, G.; Leroy, Y.; Fournet, B.; Ricart, G. CollisionalActivation Tandem Mass Spectrometry of Sodium Adduct Ions of Methylated Oligosaccharides: Sequence Analysis and Discrimination between Alpha-NeuAc- $(2 \rightarrow 3)$ and Alpha-NeuAc- $(2 \rightarrow 6)$ Linkages. Carbohydr. Res. 1991, 221, 209-217.

66. Mechref, Y.; Novotny, M. V.; Krishnan, C. Structural Characterization of Oligosaccharides Using MALDI-TOF/TOF Tandem Mass Spectrometry. Anal. Chem. 2003, 75, 4895-4903.

67. Haselmann, K. F.; Jorgensen, T. J.; Budnik, B. A.; Jensen, F.; Zubarev, R. A. Electron Capture Dissociation of Weakly Bound Polypeptide Polycationic Complexes. Rapid Commun. Mass Spectrom. 2002, 16, 2260 2265.

68. Horn, D. M.; Breuker, K.; Frank, A. J.; McLafferty, F. W. Kinetic Intermediates in the Folding of Gaseous Protein Ions Characterized by Electron Capture Dissociation Mass Spectrometry. J. Am. Chem. Soc. 2001, 123, 9792-9799

69. Xie, Y.; Zhang, J.; Yin, S.; Loo, J. A. Top-Down ESI-ECD-FT-ICR Mass Spectrometry Localizes Noncovalent Protein-Ligand Binding Sites. J. Am. Chem. Soc. 2006, 128, 14432-14433.

70. Chalmers, M. J.; Kolch, W.; Emmett, M. R.; Marshall, A. G.; Mischak, H. Identification and Analysis of Phosphopeptides. J. Chromatogr. B 2004, 803, 111-120.

71. Mann, M.; Ong, S. E.; Gronborg, M.; Steen, H.; Jensen, O. N.; Pandey, A. Analysis of Protein Phosphorylation Using Mass Spectrometry: Deciphering the Phosphoproteome. Trends Biotechnol. 2002, 20, 261-268.

72. McLachlin, D. T.; Chait, B. T. Analysis of Phosphorylated Proteins and Peptides by Mass Spectrometry. Curr. Opin. Chem. Biol. 2001, 5, 591-602. 